\title{
Factors Predicting the Relapse of Radiation-Induced Organizing Pneumonia after Breast-Conserving Therapy
}

\author{
Yukinori Okada1, Shingo Sakamoto1, Tatsuyuki Abe1, Mio Shinozaki', Hiromichi Gomi1, \\ Yoshihide Kanemaki², Shin Matsuoka1, Yasuo Nakajima1 \\ ${ }^{1}$ Department of Radiology, St. Marianna University School of Medicine, Kawasaki, Japan \\ ${ }^{2}$ Department of Radiology, Breast and Imaging Center, St. Marianna University School of Medicine, \\ Kawasaki, Japan \\ Email: igaueno512@yahoo.co.jp
}

Received 6 August 2015; accepted 13 September 2015; published 16 September 2015

Copyright (C) 2015 by authors and Scientific Research Publishing Inc.

This work is licensed under the Creative Commons Attribution International License (CC BY). http://creativecommons.org/licenses/by/4.0/

\section{Abstract}

We investigated the factors predicting radiation-induced organizing pneumonia (RIOP) relapse after tangential breast irradiation. The participants included 23 patients diagnosed with RIOP at the St. Marianna University School of Medicine Hospital between January 2008 and March 2015. Relapse was defined as the appearance of new lesions on diagnostic images during follow-up or after commencing treatment. The relapse-free survival rate and the following 9 parameters were compared between patients with and without RIOP relapse: 1) age (less than vs. equal to or more than the median); 2) white blood cell count (less than vs. equal to or more than the median); 3 ) C-reactive protein (CRP) level at the time of RIOP diagnosis (less than normal, more than normal/ less than borderline, and more than borderline); 4) boost irradiation (yes vs. no); 5) maximum lung depth on linacgraphy (less than vs. equal to or more than the median); 6) hormone therapy (yes vs. no); 7) chemotherapy (yes vs. no); 8) RIOP ratio in the whole lung (less than vs. equal to or more than the median) at the time of RIOP diagnosis; and 9) use of corticosteroids (yes vs. no). The Kaplan-Meier method was used for statistical analysis, with relapse as the cutoff. The follow-up period spanned the date of RIOP onset to May 30, 2015. The level of significance for 2 -sided tests was $p<0.05$. Relapse was evident in 14 patients $(60.8 \%)$. The relapse-free survival rate was significantly greater in the normal CRP group (less than $0.30 \mathrm{mg} / \mathrm{dl}$ ) than in the abnormal CRP group (more than $0.36 \mathrm{mg} / \mathrm{dl})(p=0.044)$ and in the normal/borderline CRP group (less than $0.36 \mathrm{mg} / \mathrm{dl}$ ) than in the high CRP group (more than $0.70 \mathrm{mg} / \mathrm{dl})(p<0.01)$. The CRP level at RIOP onset may be a useful predictor of relapse after breast-conserving therapy. 


\section{Keywords}

\section{Radiation-Induced Organizing Pneumonia, Breast-Conserving Therapy, Tangential Irradiation, C-Reactive Protein}

\section{Introduction}

Breast cancer is currently the most common type of cancer among Japanese women [1] [2]. Most patients with early breast cancer are treated by breast-conserving therapy involving partial mastectomy, followed by postoperative radiotherapy of the remaining breast tissue [3]. Tangential irradiation is a widely used technique in breast-conserving therapy. The main complication of tangential irradiation is fibrotic change in the irradiated lung field. However, in a few patients, pulmonary infiltrates have been reported to appear both inside and outside the irradiated lung field. This disorder is classified as radiation-induced organizing pneumonia (RIOP). In 1998, Crestani et al. [4] studied 15 patients with RIOP. The diagnosis of RIOP was based on the criteria proposed by Crestani et al., which included: a) a history of radiotherapy to the breast within the last 12 months; b) the presence of general and/or respiratory symptoms for $\geq 2$ weeks; c) the detection of pulmonary infiltrates outside the radiation field; and d) no specific etiology [4]. The incidence of RIOP after tangential irradiation was reported to be approximately $1.5 \%-2.1 \%$. Additionally, corticosteroids are used in the treatment of RIOP, but relapse is observed in some patients [5]. Otani et al. [6] investigated 26 cases of RIOP and found that although corticosteroids did improve symptoms, their use in itself was a risk factor for relapse. However, there are no established criteria for the use, initial dose, and dose reduction rate of corticosteroids. In practice, the RIOP treatment plan depends on the experience of the doctor. The purpose of this study was to investigate other factors predicting the relapse of RIOP.

\section{Patients and Methods}

\subsection{Patient Selection}

We reviewed the radiological information system and medical history charts. Subsequently, we selected patients who had developed RIOP at the St. Marianna University School of Medicine Hospital between January 2008 and March 2015 by using medical records and image interpretation terminals. The diagnosis of RIOP was based on the criteria proposed by Crestani et al. [4]. However, Ogo et al. reported that $10 \%-15 \%$ of patients with RIOP have no symptoms [5]. In addition, Otani et al. reported that asymptomatic patients who were suspected to have RIOP based on their clinical courses were included in their study [6]. Therefore, we also included 1 asymptomatic patient in the present study based on the clinical course.

Patients in whom the radiation field included the supraclavicular and parasternal areas were excluded from the sample, as this would result in an increase in the lung volume in the radiation field, and the possibility that this would affect pneumonia could not be eliminated. Although RIOP may be difficult to differentiate from other conditions such as bacterial pneumonia, all patients underwent chest computed tomography (CT) at onset, and the final diagnosis was based on the interpretation of the diagnostic imaging radiologist as well as other factors such as the response to antibiotic treatment and culture results.

This study was approved by the Clinical Research Institutional Review Board of the St. Marianna University School of Medicine Hospital (approval number 2973). The patients' characteristics are shown in Table 1.

\subsection{Patient Characteristics}

In total, 23 patients were diagnosed with RIOP, all of whom were female non-smokers. The median patient age was 58 years (range, 44 - 75 years), and the median duration from the end of radiotherapy to the diagnosis of RIOP was 4 months (range, 1 - 10.5 months). No patient had a history of collagen disease, interstitial pneumonia, or other pulmonary disease.

\subsection{Breast Cancer}

Of the 23 patients, 16 had cancer in the right breast, 5 patients had cancer in the left breast, and 2 patients had 
Table 1. Characteristics of patients with RIOP.

\begin{tabular}{|c|c|}
\hline Factor & Patients' characteristics \\
\hline Sex & All female \\
\hline Age & Median 58 years (range, 44 - 75 years) \\
\hline Relapse & $\begin{array}{l}\text { Yes: } 14 \text { patients } \\
\text { No: } 9 \text { patients }\end{array}$ \\
\hline Interval between the final irradiation dose and RIOP diagnosis & Median 4 months (range, 1 - 10.5 months) \\
\hline Pathology & $\begin{array}{l}\text { IDC: } 21 \text { lesions } \\
\text { DCIS: } 4 \text { lesions }\end{array}$ \\
\hline TNM & $\begin{array}{l}\text { TisN0M0: } 4 \text { lesions } \\
\text { T1N0M0: } 21 \text { lesions }\end{array}$ \\
\hline Radiation dose & $\begin{array}{c}50 \mathrm{~Gy} / 25 \text { fractions: } 9 \text { patients } \\
60 \mathrm{~Gy} / 30 \text { fractions: } 10 \text { patients } \\
42.56 \mathrm{~Gy} / 16 \text { fractions: } 1 \text { patient } \\
53.2 \mathrm{~Gy} / 20 \text { fractions: } 1 \text { patient } \\
\text { Right } 50 \mathrm{~Gy} / 25 \text { fractions and left } 60 \mathrm{~Gy} / 30 \text { fractions: } 2 \text { patients }\end{array}$ \\
\hline Boost & $\begin{array}{l}\text { Yes: } 12 \text { patients } \\
\text { No: } 9 \text { patients }\end{array}$ \\
\hline White blood cell count & Median 7000/ $\mu \mathrm{l}$ (range, $4000-14,900 / \mu \mathrm{l})$ \\
\hline CRP & $\begin{array}{l}2.2 \mathrm{mg} / \mathrm{dl} \text { (range, } 0.05-15.48 \mathrm{mg} / \mathrm{dl} \text { ) } \\
\text { Normal (less than } 0.30 \mathrm{mg} / \mathrm{dl}): 5 \\
\text { Borderline }(0.36 \mathrm{mg} / \mathrm{dl}): 1 \\
\text { High (more than } 0.70 \mathrm{mg} / \mathrm{dl}): 12\end{array}$ \\
\hline Hormone therapy & $\begin{array}{l}\text { Yes: } 18 \text { patients } \\
\text { No: } 5 \text { patients }\end{array}$ \\
\hline Chemotherapy & $\begin{array}{l}\text { Yes: } 4 \text { patients } \\
\text { No: } 19 \text { patients }\end{array}$ \\
\hline RIOP ratio in the whole lung & Median 7.4\% (range, $0.7 \%$ - 17.7\%) \\
\hline Corticosteroids & $\begin{array}{l}\text { Yes: } 17 \text { patients (use methylprednisolone: } 6 \text { patients) } \\
\text { No: } 6 \text { patients }\end{array}$ \\
\hline Prednisolone per unit body weight & $0.40 \mathrm{mg} / \mathrm{kg}$ (range, $0.21-1.2 \mathrm{mg} / \mathrm{kg}$ ) \\
\hline Prednisolone dose reduction rate & Median $0.25 \mathrm{mg} /$ day (range, 0 - $0.85 \mathrm{mg} /$ day) \\
\hline
\end{tabular}

Abbreviations: RIOP, radiation-induced organizing pneumonia; TNM, tumor-node-metastasis; CRP, C-reactive protein.

bilateral breast cancer. Further, 4 of the lesions were ductal carcinomas in situ (DCISs), whereas the remaining 21 lesions were invasive ductal carcinomas (all cT1N0M0 Stage I). In one of the patients with bilateral breast cancer, both lesions were invasive ductal carcinomas, whereas in the other patient, the lesion in the right breast was an invasive ductal carcinoma and that in the left breast was a DCIS.

\subsection{White Blood Cell}

The white blood cell count was measured in 22 patients at the time of RIOP onset. The median value was $7000 / \mu \mathrm{l}$ (range, $4000-14,900 / \mu \mathrm{l}$ ). The normal range of the white blood cell count is $4300-9000 / \mu 1$. Only 2 patients had a higher than normal white blood cell count.

\subsection{C-Reactive Protein (CRP) Level}

The CRP level was measured in 22 patients at the time of RIOP onset. The median value was $2.2 \mathrm{mg} / \mathrm{dl}$ (range, $0.05-15.48 \mathrm{mg} / \mathrm{dl})$. The normal range of CRP is less than $0.30 \mathrm{mg} / \mathrm{dl}$. The CRP level was below normal (0.05 $0.24 \mathrm{mg} / \mathrm{dl})$ in 5 patients, borderline $(0.36 \mathrm{mg} / \mathrm{dl})$ in 1 patient, and above normal $(0.7-15.38 \mathrm{mg} / \mathrm{dl})$ in 16 patients. 


\subsection{KL-6}

The KL-6 level was measured in 17 patients at the time of RIOP onset. The median value was 264 IU/L (139 596 IU/L). The normal range of KL-6 is less than 400 IU/L. Only 1 patient had a higher than normal KL-6 level.

\subsection{Hormone Therapy}

Of the 23 patients, 18 were receiving hormone therapy at the time of RIOP onset, which comprised letrozole, anastrozole, tamoxifen, and leuprorelin in 7, 4, 6, and 1 patient, respectively.

\subsection{Chemo Therapy}

Of the 23 patients, 4 were receiving chemotherapy at the time of RIOP onset, among whom, 3 received 4 courses of cyclophosphamide + epirubicin, followed by 4 courses of docetaxel + trastuzumab. The other patient completed 1 course of FEC100 (5-fluorouracil + epirubicin + cyclophosphamide, followed by 4 courses of docetaxel and trastuzumab).

\subsection{Radiation Therapy}

The 25 lesions in the 23 patients were treated via tangential radiation of the entire breast. Two patients received radiotherapy at other hospitals, and the remaining 21 received treatment at our hospital. In all cases, 6-MV X-rays were used, and the radiation field was modified using a multileaf collimator. The dose was 50 Gy/25 fractions for 9 patients, 60 Gy/30 fractions (whole breast 50 Gy/25 fractions, and tumor bed 10 Gy/5 fractions) for 10 patients, $42.56 \mathrm{~Gy} / 16$ fractions for 1 patient, and $53.2 \mathrm{~Gy} / 20$ fractions (whole breast $42.56 \mathrm{~Gy} / 16$ fractions, and tumor bed $10.64 \mathrm{~Gy} / 4$ fractions) for 1 patient. For both patients with bilateral breast cancer, the dose was $50 \mathrm{~Gy} / 25$ fractions for the right breast and $60 \mathrm{~Gy} / 30$ fractions for the left breast. We defined the additional irradiation provided for the tumor bed after whole breast irradiation as "boost therapy”. In total, 13 patients received boost therapy for the tumor bed.

In our hospital, the median value for the maximum lung depth on linacgraphy was $2 \mathrm{~cm}$ (range $1.5-2.5 \mathrm{~cm}$ ). For both patients with bilateral breast cancer, the maximum lung depth on linacgraphy was $2 \mathrm{~cm}$ in both the left and right radiation fields.

\subsection{RIOP Ratio in the Whole Lung}

We obtained a CT image at the time of RIOP onset using the Pinnacle 3 radiation treatment planning system (Hitachi Medical Corporation, Tokyo, Japan) and imputed the RIOP area as a target. We defined both airspace consolidation and ground glass opacity as RIOP areas. The contouring of RIOP was carried out by consulting two radiation oncologists (O.Y. had 11 years of experience, A.T. had 27 years of experience). We divided the RIOP volume $\left(\mathrm{cm}^{3}\right)$ by the whole lung volume $\left(\mathrm{cm}^{3}\right)$ and calculated the RIOP ratio in the whole lung. The median RIOP ratio in the whole lung was $7.4 \%$ (range, $0.7 \%-17.7 \%$ ).

\subsection{Corticosteroids}

In total, 17 patients were taking corticosteroids. All of these patients were administered prednisolone with a median dose of $25 \mathrm{mg}$ (range, 10 - $60 \mathrm{mg}$ ). Further, 6 patients started treatment with methylprednisolone. Of these, 2, 1, 2, and 1 patient received a starting dose of 125, 250, 500, and $1000 \mathrm{mg}$, respectively. The median dose of prednisolone per unit body weight was $0.40 \mathrm{mg} / \mathrm{kg}$ (range, $0.21-1.2 \mathrm{mg} / \mathrm{kg}$ ). The prednisolone dose reduction rate was obtained by dividing the time of starting prednisolone administration by the number of days for which it was taken in the non-relapse group and by then dividing the dose of prednisolone from the first dose to onset by the number of days until relapse. However, 1 patient received corticosteroid therapy in another hospital, and the prednisolone dose reduction rate could not be calculated. The median prednisolone dose reduction rate was $0.25 \mathrm{mg} /$ day (range, 0 - $0.85 \mathrm{mg} /$ day).

\subsection{Statistical Analysis}

All statistical analyses were performed using EZR (Saitama Medical Center, Jichi Medical University), which is 
a graphical user interface of the $\mathrm{R}$ software program (the $\mathrm{R}$ Foundation for Statistical Computing, version 2.13.0). More precisely, it is a modified version of the $\mathrm{R}$ commander (version 1.6-3) that includes statistical functions that are frequently used in biostatistics. Two-tailed significance was set at $\mathrm{p}=0.05$. The relapse-free survival rate was calculated using the life table method. Additionally, the Kaplan-Meier method and log-rank test were used to analyze single-variable data, with relapse as the cutoff. Relapse-free survival rates were calculated using the Kaplan-Meier method, starting from the day on which RIOP was first detected by CT. The final observation date was May 30, 2015. The follow-up period ranged from 2 to 69 months, with a mean of 12.2 months.

\section{Results}

In total, 21 patients received radiotherapy at our hospital, and 2 patients received radiotherapy at a different hospital. In our hospital, from January 2008 to March 2015, RIOP was evident in 21 of the 1807 tangentially irradiated patients $(1.16 \%)$. The median interval between the final radiation dose and the RIOP diagnosis was approximately 4 months (range, 1 - 10.5 months). Relapse was evident in 14 of the 23 patients (60.8\%). All patients were alive as of May 30, 2015.

To determine the factors influencing relapse in patients with RIOP, we compared the relapse-free survival rate and the following 9 parameters between patients with and without RIOP relapse: 1) age (less than vs. equal to or more than the median); 2) white blood cell count (less than vs. equal to or more than the median) at the time of RIOP diagnosis; 3) CRP level at the time of RIOP diagnosis (less than the normal level vs. more than the normal level/less than borderline vs. more than borderline); 4) boost irradiation (yes vs. no); 5) maximum lung depth on linacgraphy (l less than vs. equal to or more than the median); 6) hormone therapy (yes vs. no); 7) chemotherapy (yes vs. no); 8) RIOP ratio in the whole lung (less than vs. equal to or more than the median) at the time of RIOP diagnosis; and 9) use of corticosteroids (yes vs. no). In the group with corticosteroid use, we compared the relapse-free survival rate and the following 2 parameters: methylprednisolone use (yes vs. no) and dose reduction rate (less than vs. equal to or more than the median).

The Kaplan-Meier method and log-rank test revealed that the relapse-free survival rate was significantly greater in the normal CRP group (less than $0.30 \mathrm{mg} / \mathrm{dl}$ ) than in the abnormal CRP group (more than $0.36 \mathrm{mg} / \mathrm{dl}$ ) $(p=0.044)$ (Figure 1). Similarly, the relapse-free survival rate was significantly greater in the normal/borderline CRP group (less than $0.36 \mathrm{mg} / \mathrm{dl}$ ) than in the high CRP group (more than $0.70 \mathrm{mg} / \mathrm{dl})(p<0.01)$ (Figure 2). The cutoff value for the CRP level was $0.70 \mathrm{mg} / \mathrm{dl}$, and the area under the curve was 0.709 (95\% confidence interval $=0.467-0.952$ ) (Figure 3). In the group with corticosteroid use, the Kaplan-Meier method and log-rank test revealed that the relapse-free survival rate was significantly greater in the group without methylprednisolone use than in the group with methylprednisolone use $(p<0.01)$ (Figure 4). However, there was no significant difference in relapse-free survival rates according to other factors. The results of the Kaplan-Meier method and logrank tests are shown in Table 2.

\section{Discussion}

In 1995, Bayle et al. were the first to describe organizing pneumonia related to breast-conserving therapy [7]. Subsequently, a nationwide questionnaire survey of major medical institutions was conducted in Japan in 1999, and it was found that the incidence of lesions in the lungs outside the radiation field was $1.5 \%$ - 2.1\% between 1983 and 2000 [5]. Later, Otani et al. reported an incidence of 1.1\% [6]. Further, Katayama et al. reported that age ( $\geq 50$ years) and concomitant hormone therapy were risk factors for RIOP [8]. Murofushi et al. reported that older age ( $\geq 52$ years) and smoking were the significant factors associated with RIOP [9]. However, Crestani et al. reported that the influence of hormone therapy on the incidence of RIOP was not clear [4]. Thus, the risk factors for RIOP remain unclear. Some studies reported that RIOP has a good prognosis. For instance, Yamamoto et al. reported no severe cases or deaths among the 9 patients diagnosed with RIOP in their study [10]. Similarly, Ogo et al. reported no deaths among the 12 patients diagnosed with RIOP in their study [11]. In our study, the incidence of RIOP in our hospital was $1.2 \%$, and there were no deaths. Indeed, this result is generally consistent with that of previous studies.

Several studies addressed the issue of relapse of RIOP. Arbetter et al. [12] reported that the relapse rate of RIOP was 50\% (3 of 6 patients). In addition, relapse rates of RIOP of 50\% (8 of 16 patients), $40 \%$ (2 of 5 patients), 33\% (4 of 12 patients), and 57.7\% (15 of 26 patients) were reported by Katayama et al. [8], Miwa et al. 


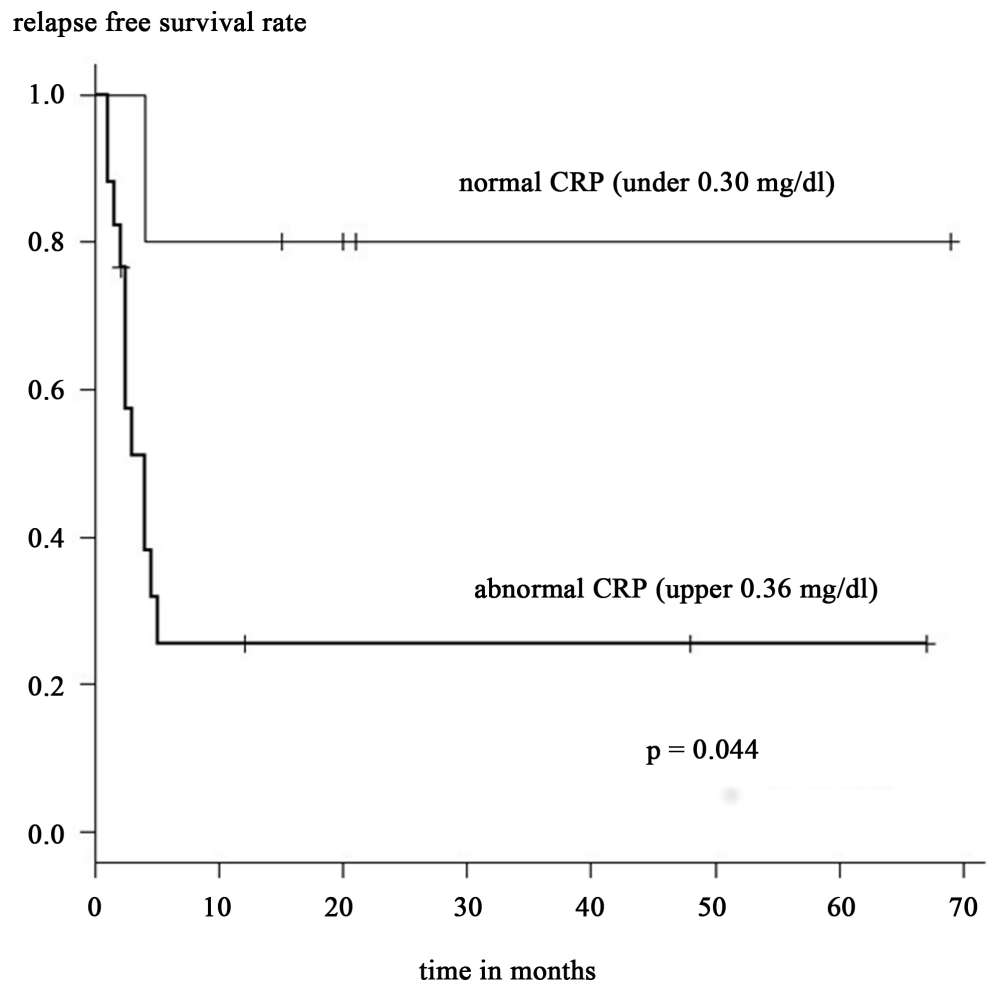

Figure 1. The C-reactive protein (CRP) level (normal vs. abnormal) at the time of onset of radiation-induced organizing pneumonia and the relapse-free survival rate.

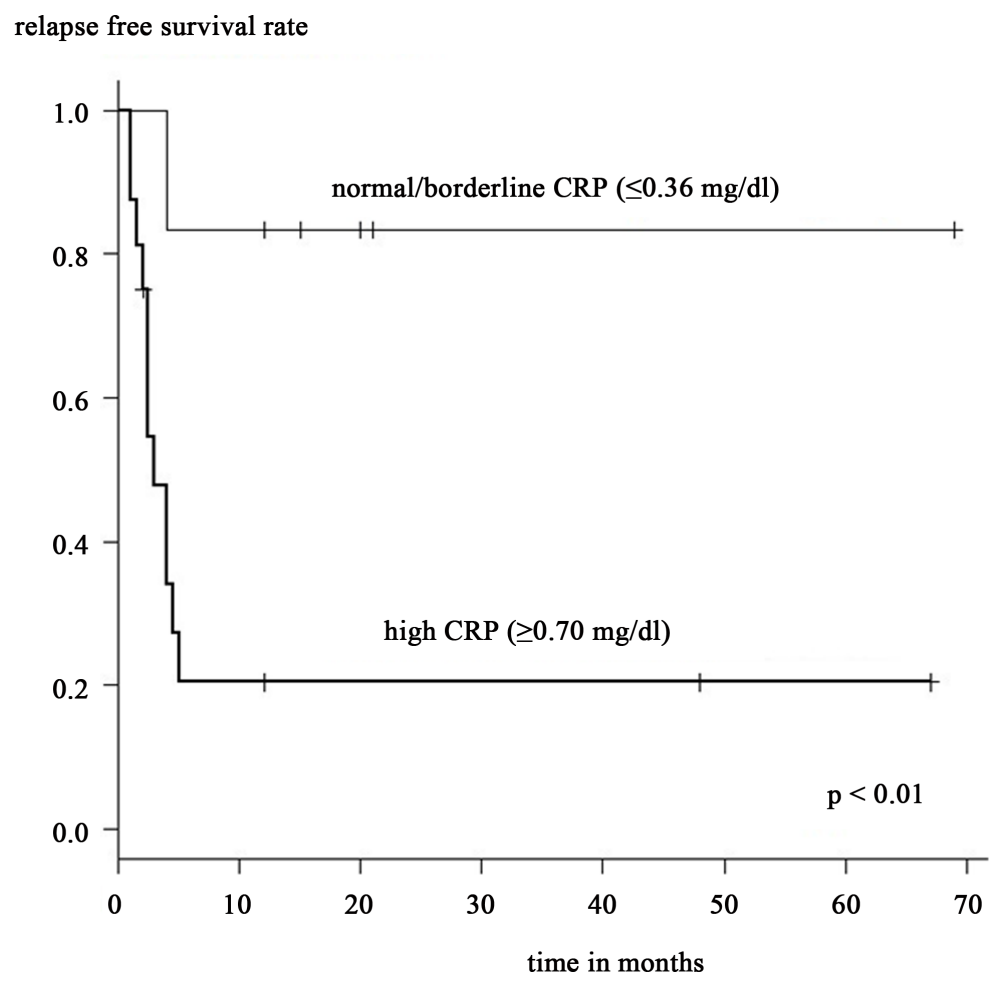

Figure 2. The C-reactive protein (CRP) level (normal/borderline vs. high) at the time of onset of radiation-induced organizing pneumonia and the relapse-free survival rate. 


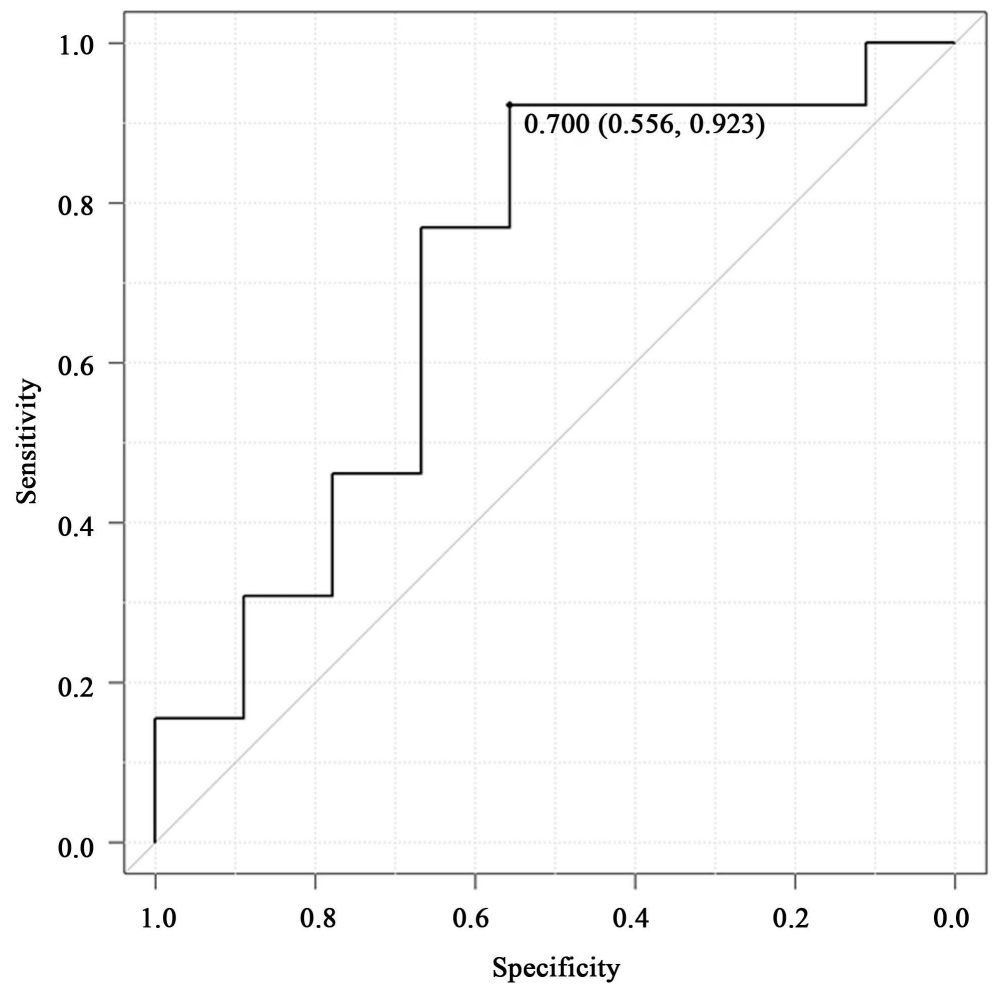

Figure 3. The C-reactive protein level at the time of onset of radiation-induced organizing pneumonia and the area under the curve.

relapse free survival rate

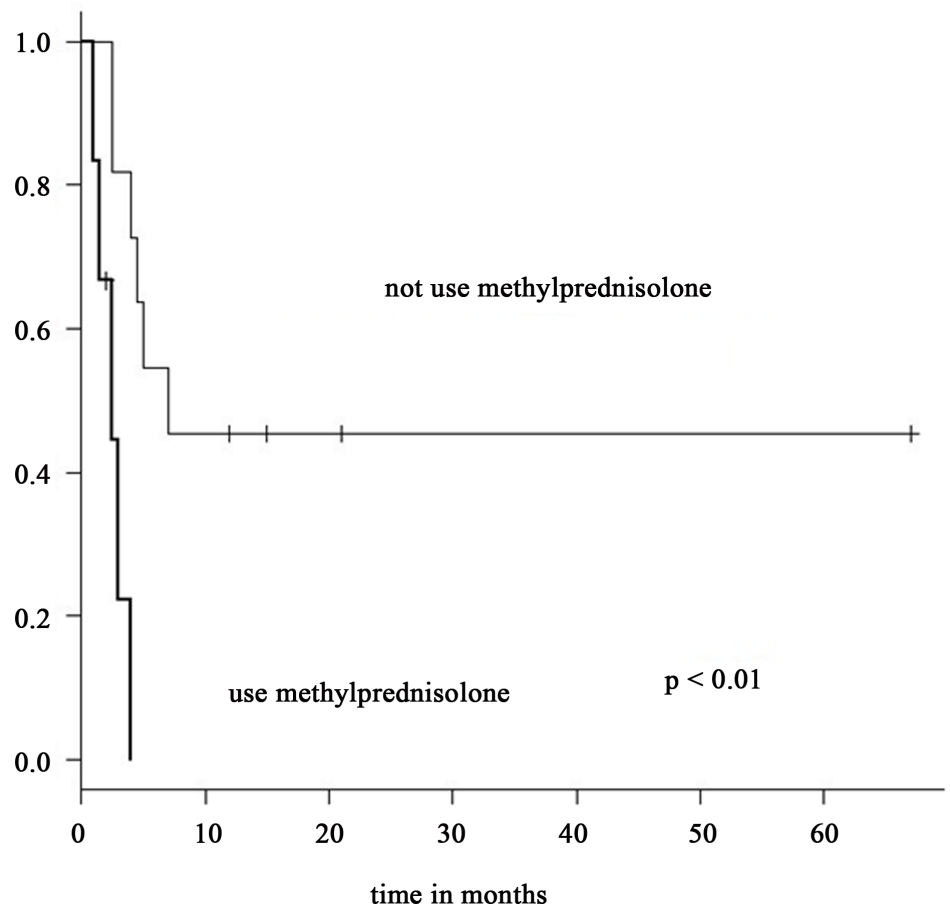

Figure 4. Relapse-free survival rate of patients with radiation-induced organizing pneumonia according to the use of methylprednisolone. 
Table 2. Relapse of RIOP and the factors investigated

\begin{tabular}{|c|c|c|c|c|}
\hline \multicolumn{2}{|c|}{ Factors investigated } & Recurrence $(\mathrm{n}=14)$ & No recurrence $(n=9)$ & $p$ value \\
\hline Age & $\begin{array}{l}\geq \text { Median } \\
\leq \text { Median }\end{array}$ & $\begin{array}{l}9 \\
5\end{array}$ & $\begin{array}{l}5 \\
4\end{array}$ & 0.516 \\
\hline White blood cell & $\begin{array}{l}\geq \text { Median } \\
\leq \text { Median }\end{array}$ & $\begin{array}{l}4 \\
4\end{array}$ & $\begin{array}{l}8 \\
6\end{array}$ & 0.307 \\
\hline CRP & $\begin{array}{c}\text { Normal } \\
\text { abnormal }\end{array}$ & $\begin{array}{c}1 \\
12\end{array}$ & $\begin{array}{l}4 \\
5\end{array}$ & $0.044^{*}$ \\
\hline CRP & Normal/borderline high & $\begin{array}{c}1 \\
11\end{array}$ & $\begin{array}{l}5 \\
5\end{array}$ & $<0.01^{*}$ \\
\hline Boost & $\begin{array}{l}\text { Yes } \\
\text { No }\end{array}$ & $\begin{array}{l}6 \\
8\end{array}$ & $\begin{array}{l}6 \\
3\end{array}$ & 0.529 \\
\hline Maximum lung depth & $\begin{array}{l}\geq \text { Median } \\
<\text { Median }\end{array}$ & $\begin{array}{l}7 \\
4\end{array}$ & $\begin{array}{l}7 \\
3\end{array}$ & 0.411 \\
\hline Hormone therapy & $\begin{array}{l}\text { Yes } \\
\text { No }\end{array}$ & $\begin{array}{c}10 \\
4\end{array}$ & $\begin{array}{l}8 \\
1\end{array}$ & 0.495 \\
\hline Chemotherapy & $\begin{array}{l}\text { Yes } \\
\text { No }\end{array}$ & $\begin{array}{c}4 \\
10\end{array}$ & $\begin{array}{l}0 \\
9\end{array}$ & 0.333 \\
\hline RIOP ratio in the whole lung & $\begin{array}{l}\text { Yes } \\
\text { No }\end{array}$ & $\begin{array}{l}8 \\
6\end{array}$ & $\begin{array}{l}4 \\
5\end{array}$ & 0.493 \\
\hline Corticosteroids & $\begin{array}{l}\text { Yes } \\
\text { No }\end{array}$ & $\begin{array}{c}11 \\
3\end{array}$ & $\begin{array}{l}6 \\
3\end{array}$ & 0.658 \\
\hline Methylprednisolone & $\begin{array}{l}\text { Yes } \\
\text { No }\end{array}$ & $\begin{array}{l}5 \\
6\end{array}$ & $\begin{array}{l}1 \\
5\end{array}$ & $<0.01^{*}$ \\
\hline Prednisolone dose reduction rate & $\begin{array}{l}\geqslant \text { Median } \\
\leq \text { Median }\end{array}$ & $\begin{array}{l}5 \\
5\end{array}$ & $\begin{array}{l}4 \\
2\end{array}$ & 0.274 \\
\hline
\end{tabular}

Abbreviations: RIOP, radiation-induced organizing pneumonia; CRP, C-reactive protein.

[13], Kubo et al. [14], and Otani et al. [6], respectively. Further, Otani et al. reviewed 11 papers on RIOP and found that the overall relapse rate was 47.6\% (29 of 61 patients) [6]. Similarly, Ozawa et al. reviewed some studies on RIOP and found that the overall relapse rate was $56 \%$ (9 of 21 patients) [15]. The RIOP relapse rate in our study was somewhat higher at $60.8 \%$ (14 of 23 patients). However, this finding may have been affected by factors such as different intervals between diagnostic imaging in different studies and the fact that the follow-up period was not consistent.

Corticosteroids are frequently used in the treatment of RIOP. However, in some reports, corticosteroid use in itself has been reported as a risk factor for relapse. For instance, Otani et al. found that over a 6-month follow-up period, 5 of 7 patients treated with corticosteroids experienced relapse of RIOP, compared to 3 of 19 patients who did not receive corticosteroids. Thus, they confirmed that although corticosteroids did improve symptoms, their use was a risk factor for relapse [6]. Other reported relapse rates for patients treated with corticosteroids are 100\% (4 of 4 patients) [16], 40\% (2 of 5 patients) [13], and 80\% (12 of 15 patients) [4]. In contrast, Ogo et al. reported that $18.5 \%$ of patients with RIOP recovered during follow-up without the use of corticosteroids [11]. Indeed, these studies suggest that corticosteroid use may be a risk factor for relapse. However, there are no established criteria for the use of corticosteroids, their dosage, or dose reduction rate at present. Therefore, patient selection bias cannot be excluded in these studies. Therefore, the present study attempted to identify other factors that can predict the relapse of RIOP.

RIOP is classified as a type of interstitial pneumonia. Okada et al. found that of 37 patients with organizing pneumonia, KL-6 levels were normal in 20 patients and high in 17 patients. Relapse after the start of prednisolone administration was evident in 2 of 16 patients with normal KL-6 levels and in 6 of 16 patients with elevated KL-6 levels. Although this difference was not statistically significant, it is evident that relapse tended to be more common among patients with elevated KL-6 levels [17]. In our study, however, only 1 patient exhibited an abnormal KL-6 level. The KL-6 level was also within normal limits for all 5 patients in Miwa et al.'s study [13] and all 16 patients in Katayama et al.'s study [8]. Similarly, Yamamoto et al. also reported that all 10 patients had KL-6 levels within normal limits [10]. It is evident that although RIOP is classified as a type of interstitial 
pneumonia, KL-6 does not increase the possibility of the occurrence of RIOP after breast-conserving therapy, indicating that it cannot be used as a clinical indicator. Although no studies have addressed the association between RIOP after breast-conserving therapy and CRP levels, Otani et al. reported that the CRP level, measured in 19 of 26 patients, was elevated in 15 (78.9\%) patients [6]. We therefore investigated the role of the CRP level based on the hypothesis that it might reflect disease activity. In the present study, the relapse-free survival rate was significantly greater in the normal CRP group (less than $0.30 \mathrm{mg} / \mathrm{dl}$ ) than in the abnormal CRP group (more than $0.36 \mathrm{mg} / \mathrm{dl}$ ). The same was observed for the normal and borderline CRP groups (less than $0.36 \mathrm{mg} / \mathrm{dl}$ ) compared with the high CRP group (more than $0.70 \mathrm{mg} / \mathrm{dl}$ ). However, the reason for the high frequency of relapse among patients with abnormal/high CRP levels is unclear. Interestingly, in a recent report on cryptogenic organizing pneumonia (COP) relapse, Nishino et al. reported that in 26 patients with organizing pneumonia, multifocal fibrin deposits were significantly associated with COP relapse [18]. Moreover Nagata et al. reported that in 41 patients with organizing pneumonia, intra-alveolar fibrin deposition (IAFD) was significantly associated with high CRP values, and high CRP values and/or IAFD predicted the relapse of organizing pneumonia within 6 months to 1 year [19]. We believe that the abnormal CRP level observed in 1 patient in our study was associated with IAFD and RIOP relapse. Nagata et al. reported that their study included 7 patients with collagen vascular disease and 5 patients with chronic obstructive pulmonary disease. Moreover, 26 of their patients were male, and 15 were female. Further, their patients' backgrounds were heterogeneous. Conversely, in our study, the patients' backgrounds were homogeneous. Additionally, all of our patients were female, and none had collagen vascular disease or other pulmonary diseases. However, CRP levels at the time of RIOP onset were associated with RIOP relapse. We believe that the CRP level at the time of RIOP onset may be a useful factor for predicting RIOP relapse following breast-conserving therapy.

There was no statistical difference with respect to factors such as the use of corticosteroids, the reason for which is unclear. We believe that the findings may have been affected by 2 factors: patient selection bias and the corticosteroid dose. The probability that patients with severe RIOP were treated with corticosteroids and patients with mild RIOP were not treated with corticosteroids could not be discounted. Further, the probability that the corticosteroid dose may have affected the risk of RIOP relapse could not be eliminated. Bradley et al. recommended an initial dose of corticosteroids for COP of 0.75 - $1 \mathrm{mg} / \mathrm{kg} /$ day oral prednisolone (or equivalent), whereas fulminant disease may require high-dose intravenous methylprednisolone (1.0 g/day for 3 days) [20]. Otani et al. reported that all treated patients were administered $60 \mathrm{mg}$ of prednisolone as an initial dose [6]. However, in our study, the median dose of prednisolone per unit body weight was $0.40 \mathrm{mg} / \mathrm{kg}$. Additionally, the relapse-free survival rate was significantly greater in the group without methylprednisolone use group than in the group with methylprednisolone use. Therefore, the probability that high-dose corticosteroids affect the risk of RIOP relapse could not be dismissed.

Our study had a number of limitations. It was a single-center study conducted on a small number of patients. At present, no study has included more patients than that by Ogo et al. (33 patients) [11], followed by those by Otani et al. (26 patients) [6], Katayama et al. (16 patients) [8], and Crestani et al. (15 patients) [4]. Evidently, the present study and previous studies involved only a small number of patients. Moreover, the relationship between CRP levels and RIOP relapse was not explained sufficiently. RIOP after tangential irradiation is an uncommon condition, and a prospective clinical study is therefore problematic. The fact that this was a retrospective study also meant that there was wide variation in variables such as the time of onset, blood sample findings, imaging findings, and follow-up periods. Future large-scale, multicenter studies are therefore recommended.

\section{Conclusion}

Our results suggest that the CRP level at the time of RIOP onset is a useful factor for predicting the relapse of RIOP following breast-conserving therapy.

\section{Conflicts of Interest}

All authors have no conflicts of interest in this study.

\section{References}

[1] Makita, M., Iwase, T., Tada, T., Takahashi, K., Tada, K., Nishimura, S., Yoshimoto, M., Kasumi, F., Akiyama, F. and 
Sakamoto, G. (2004) The Site and Timing of the First Recurrence of Breast Cancer. Japanese Journal of Breast Cancer, 19, 343-351.

[2] Pivot, X., Asmar, L., Hortobagyi, G.N., Theriault, R., Pastorini, F. and Buzdar, A.R. (2003) Retrospective Study of First Indicators of Breast Cancer. Breast Cancer, 10, 335-340.

[3] Veronesi, U., Cascinelli, N., Mariani, L., Greco, M., Saccozzi, R., Luini, A., Aguilar, M. and Marubini, E. (2002) Twenty-Year Follow-Up of a Randomized Trial Comparing Total Mastectomy, Lumpectomy, and Lumpectomy plus Irradiation for the Treatment of Invasive Breast Cancer. The New England Journal of Medicine, 347, 1233-1241. http://dx.doi.org/10.1056/NEJMoa020989

[4] Crestani, B., Valeyne, D., Roden, S., Wallaert, B., Dalphin, J.C. and Cordier, J.F. (1998) Bronchiolitis Obliterans Organizing Pneumonia Syndrome Primed by Radiation Therapy to the Breast. American Journal of Respiratory and Critical Care Medicine, 158, 1929-1935. http://dx.doi.org/10.1164/ajrccm.158.6.9711036

[5] Ogo, E., Fujimoto, K., Hayabuchi, N., Mitsumori, M., Yamamoto, C., Furukawa, M., Ogawa, Y., Sekiguchi, K., Soejima, T., Hirokawa, Y., Dodo, Y. and Nakamura, K. (2002) Report of a Questionnaire Survey on Lung Damage after Breast-Conserving Therapy. Japanese Journal of Clinical Radiology, 47, 313-322. (In Japanese)

[6] Otani, K., Nishiyama, K., Ito, Y., Kawaguchi, Y. and Inaji, H. (2014) Steroid Treatment Increases the Recurrence of Radiation-Induced Organizing Pneumonia after Breast-Conserving Therapy. Cancer Medicine, 3, 947-953. http://dx.doi.org/10.1002/cam4.255

[7] Bayle, J.Y., Nesme, P., Béjui-Thivolet, F., Loire, R., Guérin, J.C. and Cordier, J.F. (1995) Migratory Organizing Pneumotitis Primed by Radiation Therapy. European Respiratory Journal, 8, 322-326. http://dx.doi.org/10.1183/09031936.95.08020322

[8] Katayama, N., Sato, S., Katsui, K., Takemoto, M., Tsuda, T., Yoshida, A., Morito, T., Nakagawa, T., Mizuta, A., Waki, T., Niiya, H. and Kanazawa, S. (2000). Bronchiolitis Obliterans Organizing Pneumonia Syndrome in Breast-Conserving Therapy for Early Breast Cancer: Radiation-Induced Lung Toxicity. International Journal of Radiation Oncology, Biology, Physics, 4, 751-755.

[9] Murofushi, K., Oguchi, M., Gosho, M., Kozuka, K. and Sakurai, H. (2015) Radiation Induced Bronchiolitis Obliterans Organizing Pneumonia (BOOP) Syndrome in Breast Cancer Patients Is Associated with Age. Radiation Oncology, 10, 103-113. http://dx.doi.org/10.1186/s13014-015-0393-9

[10] Yamamoto, Y., Murata, K., Sakashita, K., Miyamoto, M., Wada, A., Kashiyama, T., Fujita, A. and Takamori, M. (2013) Radiation-induced Lung Injury outside the Irradiated Area after Radiation Therapy for Breast Cancer. Annals of the Japanese Respiratory Society, 2, 169-174. (In Japanese)

[11] Ogo, E., Komaki, R., Abe, T., Uchida, M., Fujimoto, K., Suzuki, G., Tsuji, C., Suefuji, H., Etou, H., Hattori, C., Watanabe, Y. and Hayabuchi, N. (2010) The Clinical Characteristics and Non-Steroidal Treatment for Radiation-Induced Bronchiolitis Obliterans Organizing Pneumonia Syndrome after Breast-Conserving Therapy. Radiotherapy and Oncology, 97, 95-100. http://dx.doi.org/10.1016/j.radonc.2010.02.032

[12] Arbetter, K.R., Prakash, U.B., Tazelaar, F.D. and Douuglas, W.W. (1999) Radiation-Induced Pneumonitis in the “Nonirradiated” Lung. Mayo Clinic Proceedings, 74, 27-36. http://dx.doi.org/10.4065/74.1.27

[13] Miwa, S., Morita, S., Suda, T., Suzuki, K., Hayakawa, H., Chida, K. and Nakamura, H. (2004). The Incidence and Clinical Characteristics of Bronchiolitis Obliterans Organizing Pneumonia Syndrome after Radiation Therapy for Breast Cancer. Sarcodosis Vasculitis and Diffuse Lung Diseases, 21, 212-218.

[14] Kubo, A., Osaki, K., Kawanaka, T., Furutani, S., Ikushima, H. and Nishitani, H. (2009) Risk Factors for Radiation Pneumonitis Caused by Whole Breast Irradiation Following Breast-Conserving Surgery. Journal of Medical Investigation, 56, 99-110. http://dx.doi.org/10.2152/jmi.56.99

[15] Ozawa, Y., Ida, M., Suda, T., Fujii, M., Katou, S., Hasegawa, H., Enomoto, N., Nogimura, H. and Chida K. (2005) Clinical Study of Bronchiolitis Obliterans Organizing Pneumonia (BOOP) Primed by Radiation to the Breast Cancer. Japanese Journal of Clinical Radiology, 43, 71-76. (in Japanese)

[16] Takigawa, N., Segawa, Y., Saeki, T., Kataoka, M., Ida, M., Kishino, D., Fujiwara, K., Ohsumi, S., Eguchi, K. and Takashima, S. (2000) Bronchiolitis Obliterans Organizing Pneumonia Syndrome in Breast-Conserving Therapy for Early Breast Cancer: Radiation-Induced Lung Toxicity. International Journal of Radiation Oncology, Biology, Physics, 1, 751-755. http://dx.doi.org/10.1016/S0360-3016(00)00654-4

[17] Okada, F., Ando, Y., Honda, K., Tanoue, S., Matsumoto, S. and Mori, H. (2009) Comparison of Pulmonary CT Findings and Serum KL-6 Levels in Patients with Cryptogenic Organizing Pneumonia. British Journal of Radiology, 82, 212-218. http://dx.doi.org/10.1259/bjr/72775434

[18] Nishino, M., Mathai, S.K., Schoenfeld, D., Digumarthy, S.R. and Kradin, R.L. (2014) Clinicopathologic Features Associated with Relapse in Cryptogenic Organizing Pneumonia. Human Pathology, 45, 342-345.

http://dx.doi.org/10.1016/j.humpath.2013.09.010 
[19] Nagata, N., Wakamatsu, K., Kumazoe, H., Miyazaki, H., Akagi, T., Kawasaki, M. and Watanabe, K. (2015) Clinical Significance of Intra-Alveolar Fibrin Deposition in Trans Bronchial Lung Biopsy in Patients with Organizing Pneumonia. Lung, 193, 203-208. http://dx.doi.org/10.1007/s00408-015-9689-7

[20] Bradley, B., Branley, H.M., Egan, J.J., Greaves, M.S., Hansell, D.M., Harrison, N.K., Hirani, N., Hubbard, R., Lake, F., Millar, A.B., Wallace, W.A., Wells, A.U., Whyte, M.K. and Wilsher, M.L. (2008) Interstitial Lung Disease Guideline: The British Thoracic Society in Collaboration with the Thoracic Society of Australia and New Zealand and the Irish Thoracic Society. Thorax, 63, v1-v58. http://dx.doi.org/10.1136/thx.2008.101691 